\title{
EFEITOS REAIS DA POLÍTICA MONETÁRIA: UMA DISCUSSÃO SOBRE OS MECANISMOS DE TRANSMISSÃO
}

\author{
Marcos Wagner da Fonseca ${ }^{1}$ \\ Marcos Roberto Vasconcelos ${ }^{2}$
}

\section{INTRODUÇ̃̃O}

Em sua História da análise econômica, Schumpeter (1954, cap. 6) apontou para a existência de duas grandes e antagônicas abordagens presentes no pensamento econômico: a Análise Real e a Análise Monetária. Enquanto nesta a moeda assume papel fundamental para a explicação do processo econômico, naquela os valores de longo prazo das variáveis econômicas seriam definidos apenas por fatores reais e a moeda seria mero "expediente técnico" para facilitar as transações econômicas. Como mostram Greenwald e Stiglitz (2002), ao comentarem os atuais debates teóricos referentes à economia monetária, a dicotomia indicada por Schumpeter continua válida, opondo, por exemplo, economistas de filiação novo-clássica a novo-keynesiana.

É na discussão de tal dicotomia que se insere o presente artigo. De fato, assume-se aqui a abordagem da Análise Monetária e busca-se, então, examinar como as variações na oferta monetária afetariam a economia. Em outros termos, o objetivo principal é apresentar o desenvolvimento e as principais controvérsias do debate sobre os mecanismos de transmissão monetária ao longo da segunda metade do século XX. Ênfase maior dá-se às discussões observadas na última década.

${ }^{1}$ Professor Assistente da Universidade Estadual do Oeste do Paraná UNIOESTE - Cascavel. Doutorando em Desenvolvimento Econômico - Universidade Federal do Paraná - UFPR.

${ }^{2}$ Prof. Dr. da Universidade Estadual de Maringá - UEM. 
Para cumprir este objetivo, o presente artigo, além desta introdução, está assim organizado: na próxima seção, realiza-se um breve resgate do debate em Economia Monetária até a década de 1990; na terceira seção, encaminha-se as principais posições teóricas e controvérsias concernentes aos canais de transmissão da política monetária. Por fim, encerra-se o trabalho com algumas considerações.

\section{BREVE RESGATE DO DEBATE EM ECONOMIA MONETÁRIA: PRINCIPAIS CORRENTES E CONTROVÉRSIAS}

Como exposto, dentro da história do pensamento econômico está presente uma controvérsia: a política monetária interfere ou não nas variáveis reais da economia, tais como consumo, investimento, renda, produto e emprego? Se a resposta for positiva, isto é, se a moeda for capaz de interferir nas variáveis reais, a indagação seguinte é como tal interferência ocorre. A questão não é trivial. Keynes, principal nome da abordagem Análise Monetária, estava ciente disso, como indica o seu comentário sobre os percalços da moeda na economia:

...podemos ter uma primeira idéia do modo como as variações na quantidade de moeda intervêm no sistema econômico. Contudo, se nos vemos tentados a considerar a moeda como a bebida que estimula a atividade do sistema, não nos esqueçamos que podem surgir muitos percalços entre a taça e os lábios. Embora seja de esperar que, ceteris paribus, um aumento na quantidade de moeda reduza a taxa de juros, isto não ocorrerá se a preferência do público pela liquidez aumentar mais que a quantidade de moeda; e, conquanto se possa esperar que, ceteris paribus, uma baixa taxa de juros estimule o fluxo de investimento, isto não acontecerá se a escala da eficiência marginal do capital cair mais rapidamente que a taxa de juros; quando, enfim, se possa esperar que, ceteris paribus, um aumento no fluxo de investimento faça aumentar o emprego, isso não se produzirá se a propensão a consumir estiver em declínio. Finalmente, se o emprego aumentar, os preços subirão numa proporção que depende, em parte, da forma das funções da oferta e, em parte, da tendência da taxa de salários subir em termos monetários. (KEYNES, 1985, p. 125). 
Dessa citação, percebe-se as sinuosas junções entre a moeda e o nível de produto. Dois elos se destacam: primeiro é saber como a política monetária afeta o conjunto de taxas de juros; segundo, como as variações das taxas de juros repercutem sobre as variáveis reais, o que implica tratar do comportamento dos agentes quanto à demanda por moeda, da sensibilidade do investimento à variável taxa de juros e de como a demanda agregada pode afetar o nível de emprego e de salários, chegando até o nível de preços. Dessas imbricadas passagens alimenta-se o debate, ainda inconcluso, sobre os mecanismos de transmissão monetária. Porém, antes de apresentar as principais contribuições teóricas para o tema, cabe estabelecer breves comentários metodológicos referentes à demonstração da evidência empírica das correntes principais aqui tratadas.

Em Mishkin (1998, p. 379), o processo de avaliação da evidência empírica segue dois caminhos: 1) a evidência de modelo estrutural; 2) evidência de forma reduzida. A evidência de modelo estrutural está presente no horizonte de análise dos keynesianos e define que os mecanismos de transmissão da política monetária apresentam a forma pela qual a moeda afeta a atividade econômica, construindo, para isso, um modelo estrutural. Este modelo estrutural trata a relação existente entre as diversas variáveis econômicas por meio de equações comportamentais, demonstrando passo-a-passo (quando possível) o impacto que uma modificação na quantidade de moeda (M) causa no produto (Y). Por outro lado, a evidência de forma reduzida - forma utilizada pelos monetaristas - não descreve, de modo específico, o caminho que a alteração da quantidade da moeda (M) afeta o produto (Y). Estabelece-se apenas um nexo causal, e supostamente regular, entre as variáveis. Utilizando-se os termos de Lawson (1997), a busca de evidências na forma reduzida despreza aspectos ontológicos do objeto sob análise.

Retornando para os aspectos teóricos, cumpre iniciar pela teoria que tem permeado o debate monetário desde seus primórdios: a Teoria Quantitativa da Moeda (TQM). De acordo com Costa (1994, p. 1), a TQM consiste em um conjunto de proposições interrelacionadas ou postulados sustentáculos da conclusão de que quando a quantidade de moeda torna-se abundante, seu valor ou poder de compra cai, e conseqüentemente, o índice geral de preços eleva-se. Os postulados da TQM, conforme Costa (1994), são: 
Postulado da Proporcionalidade ${ }^{3}$, da Causalidade 4 , da Neutralidade ${ }^{5}$, da Exogeneidade $^{6}$ e o da Teoria Monetária do Nível dos Preços. ${ }^{7}$

A defesa ou crítica a estes postulados caracterizou grande parte do debate sobre a teoria monetária e, por conseqüência, a execução da política monetária. Portanto, a discussão ao longo desta seção deverá guiar-se pela contribuição das correntes favoráveis e defensoras da TQM e das correntes alternativas que, de acordo com hipótese de Costa (1994), podem estabelecer uma Teoria Alternativa da Moeda.

Segundo Mishkin (1998), duas interpretações da TQM ganharam destaque no final do século XIX e início do século XX: a equação de trocas de Fischer e a abordagem de Cambridge. A equação de trocas de Fisher ${ }^{8}$ assume a seguinte forma: $\mathrm{MV}+\mathrm{M}^{\prime} \mathrm{V}^{\prime}=\mathrm{PT}$. Nela o dinheiro (M) é somente aquilo que é aceito na troca de bens, ficando de fora os depósitos à vista (M'). De acordo com Mishkin (1998), Fisher (1911) adotou como hipótese uma economia sempre no pleno emprego e presumiu uma relação fixa entre o volume de transações e o nível de produto, permitindo assim que a velocidade fosse uma variável independente e constante. Desta forma, modificações em M provocariam modificações em $P$, não alterando $\mathrm{V}$, que dependeria de condições técnicas (densidade da população, rapidez dos transportes, costumes comerciais, determinantes da poupança, tomada de crédito e uso de cheques), não mantendo qualquer relação com a quantidade de moeda (M).

O mecanismo de transmissão direta, exposto acima, apresenta uma descrição de como a quantidade de moeda pode afetar a economia, mas de acordo com os pressupostos levantados por Fisher (1911), os preços devem ser alterados e as demais variáveis podem até modificar-se por um período, mas devem voltar para seu estado normal a longo prazo.

O enfoque de Cambridge buscou acentuar o papel da moeda como reserva de valor, devido ao pressuposto de que a moeda poderia ser utilizada

${ }^{3}$ Postulado da Proporcionalidade estabelece que uma dada variação percentual no estoque nominal de moeda resultará em idêntica variação percentual no nível geral de preços.

${ }^{4}$ Postulado da Causalidade estabelece que variações monetárias precedem e causam variações no nível de preços.

${ }^{5}$ Postulado da Neutralidade estabelece que variações monetárias, não exercem influência sobre variáveis econômicas reais.

${ }^{6}$ Postulado da Exogeneidade estabelece que a oferta de moeda não é determinada pela demanda.

${ }^{7}$ Postulado da Teoria Monetária do Nível de Preços estabelece que este tende a ser influenciado predominantemente por variações na quantidade de moeda.

${ }^{8}$ De fato, como aponta Friedman (1990), tal versão da TQM foi formulada por Simon Newcomb em 1885. Coube a Irving Fischer (1911) popularizá-la. 
também para compras futuras, e não apenas para efetuar transações correntes (FRIEDMAN, 1990). Portanto, a velocidade de circulação da moeda passou a ser vista como uma demonstração do comportamento da demanda por moeda, determinada não apenas pelo nível de atividade e pelos fatores institucionais, mas também pelas expectativas empresariais em relação a todas essas variáveis. Conforme Mishkin (1998), a possibilidade da moeda ser utilizada também como reserva de valor sugeriu que o nível de riqueza das pessoas também afetasse a demanda por moeda, pois conforme crescia a riqueza do indivíduo, esse necessitaria de maior volume de moeda para manter parte de sua riqueza em ativo líquido. A equação de Cambridge $\mathrm{M}^{\mathrm{d}}=\mathrm{k} \mathrm{x}$ PY apresentou k como uma constante de proporcionalidade, semelhante à apresentada por Fisher. Todavia, permitiu que k pudesse flutuar no curto prazo em razão de as decisões sobre o uso do dinheiro para estocar riqueza supostamente dependerem dos rendimentos e retornos esperados sobre outros ativos, que também funcionariam como estoques de riqueza. Este ponto abriu margem para que a taxa de juros tivesse um papel na determinação da demanda por moeda; porém, a transmissão monetária, na equação de Cambridge, ainda continuou sendo pela via direta.

De acordo com Silva (1989, p. 50), Wicksell buscou "fugir à metafísica barata da TQM" e seus estudos sobre a relação entre poupança, investimento, juros e preços levaram-lhe a concluir que a descolagem entre a taxa de juros de mercado ou monetária (manipulável pela política monetária) e a taxa de juros natural ou real (dependente da produtividade marginal do capital físico) seria a responsável por alterações naquelas variáveis. $\mathrm{O}$ mecanismo cumulativo desenvolvido por Wicksell pode ser apresentado da seguinte forma:

Na medida em que a taxa de juros do mercado (rm) for menor que a natural (rn), haverá um prêmio artificial à despesa de capital financiada por crédito, empurrando os preços para cima até que a escassez de fundos disponíveis para empréstimos eleve rm de modo a iguala-la a rn. Há vários motivos para que os preços subam, se rm for menor que rn: em primeiro lugar, porque uma baixa taxa de juros paga pelos bancos a seus depositantes diminui o estímulo à poupança e aumenta o consumo; em segundo lugar, porque os investidores aumentarão sua demanda pelos fatores de produção. $\mathrm{O}$ aumento da renda dos agentes econômicos dará lugar a uma demanda por mercadorias de consumo, no momento em que estas tendem a decrescer, cedendo passo à atividade de investimento. A conjugação dessas duas forças levará a uma alta de preços, que persistirá enquanto rm for menor que rn. (SILVA, 1989, p. 50). 
Portanto, para Wicksell a taxa de juros deve ser entendida como o elo entre o setor real e o monetário da economia. Diferente da TQM, não é o aumento de moeda que gera inflação de demanda, mas o desvio provocado na taxa de juros de mercado em relação à sua posição de equilíbrio (taxa natural), caracterizando a existência de um mecanismo de transmissão indireto.

A predominância da Teoria Quantitativa da Moeda até a publicação da Teoria Geral do Emprego, do Juro e da Moeda, em 1936, e todas as controvérsias posteriores foi devido às contribuições dos autores neoclássicos, pois estes deram aspecto definido aos pressupostos que possibilitou a crítica em Keynes (1985), que defendeu, conforme citação realizada anteriormente, que a moeda desempenhava um importante papel na determinação das variáveis reais, interferindo na taxa de juros, no investimento, consumo, emprego e produto.

Para Keynes (1985), a demanda por moeda apresentava três motivos principais: o motivo transação, o motivo precaução e o motivo especulação. Dentro deste quadro, a moeda deixou de ser vista como neutra e passou a desempenhar um papel de reserva de valor, tanto para fins transacionais futuros como para fins precaucionais e oportunidades especulativas. Cabe uma pequena ressalva antes de prosseguir na argumentação de Keynes. A preferência pela liquidez não é o mesmo que demanda por moeda, pois preferência pela liquidez está envolvida com a riqueza (estoque) muito mais que a renda (fluxo), enquanto que a demanda por moeda está mais ligada à renda.

A retenção de moeda para transações depende da forma pela qual os agentes se comportam para efetivar seus gastos. Os indivíduos efetuam transações de acordo com a renda que recebem ao longo de determinado período. As empresas efetuam gastos para manutenção de sua atividade produtiva, conforme as necessidades de capital de giro. Portanto, o motivo transação pode ser subdividido em motivo renda e motivo negócios. Por sua vez, os motivos precaução e especulação podem ser definidos pela necessidade de retenção de moeda quanto a incertezas que os agentes têm a respeito dos acontecimentos futuros da economia. O motivo precaução indica a demanda por moeda quando há expectativa de que a taxa de juros mudará, mas não se aponta em que sentido. O motivo especulação determina a demanda por moeda quando há expectativa de que a taxa de juros provavelmente mudará para uma determinada direção. Logo, na interpretação de Keynes pode ser perfeitamente racional que um indivíduo guarde moeda, mantendo liquidez dos ativos, quando existe a possibilidade de alguma alteração na taxa de juros, que poderá dar um retorno maior do que se abrisse mão da liquidez, aplicando em ativos menos líquidos que não permitissem a 
mudança de posição e, por conseguinte, os ganhos com a alteração nas taxas de juros.

Após a publicação da Teoria Geral, Keynes apresentou um quarto motivo para retenção da moeda, o motivo financeiro (finance). Refere-se à demanda por moeda antecipada a alguma despesa discricionária planejada, sendo o gasto desse tipo mais vultoso e menos rotineiro, como o investimento em bens de capital.

Tais formas de justificar a demanda por moeda permitiram a Keynes desenvolver outro entendimento sobre o processo de formação da taxa de juros. Essa seria um prêmio pela renúncia à liquidez, pois, quando isto acontece, o indivíduo abre mão da possibilidade de realizar o gasto ou a aplicação, em outro momento, com o surgimento de melhor oportunidade.

A teoria monetária de Keynes acabou por definir que a moeda pode seguir um caminho dentro da economia e influenciar a dinâmica das variáveis reais. A preferência pela liquidez indicou que a moeda tem um papel fundamental na determinação da taxa de juros e esta pode mudar os gastos com consumo e com investimento, afetando assim o produto e a renda. Em suma, é justificável concluir que em Keynes o mecanismo de transmissão indireto foi definido com maior robustez e sutilezas.

Todavia, a leitura de economistas ingleses e norte-americanos nos anos que se seguiram à publicação da Teoria Geral, de acordo com Mishkin (1998), estabeleceu uma corrente de pensamento, que ficou conhecida por velhos keynesianos, síntese neoclássica, ou ainda, fiscalistas, não deu a devida relevância a tais sutilezas. A base de sustentação das idéias da síntese neoclássica foi a definição de que o investimento tinha uma baixa sensibilidade em relação às modificações na taxa de juros. Para Mishkin (1998), essa hipótese ganhou corpo com a observação de que uma grande queda da taxa de juros de longo prazo de 1932 a 1941 não causou correspondente elevação do nível de investimento no mesmo período.

Apoiando-se na abordagem IS-LM, a síntese neoclássica apresentou que a conseqüência do investimento ser pouco sensível às modificações na taxa de juros fazia com que a Curva IS fosse muito inclinada, sendo considerada quase vertical. Dentro desta perspectiva, seria necessária uma grande queda na taxa de juros para que o produto e o emprego aumentassem em proporções quase que desprezíveis. Assim, estaria justificada a denominação de fiscalistas a estes economistas, pois somente a alteração dos gastos governamentais poderia deslocar a Curva IS e, com isso, modificar o nível do produto e do emprego.

Durante a predominância teórica dos velhos keynesianos, alguns economistas buscavam formas alternativas de demonstrar a relevância da 
política monetária para a demanda agregada. Dentre estes economistas destaca-se Milton Friedman, o qual, com seus companheiros e discípulos da Universidade de Chicago, formou a escola denominada posteriormente como monetaristas.

Os monetaristas defendiam que o aumento na taxa de crescimento do estoque de moeda estimularia a demanda agregada e, como conseqüência, a renda nominal, sendo este o efeito de curto prazo que, de acordo com Friedman (1968), seguiria uma trajetória na qual a elevação da renda assumiria a forma de um aumento no produto e no emprego, mas não nos preços. Como as pessoas vinham esperando preços estáveis, levaria algum tempo para que as pessoas se ajustassem a um novo estado da demanda. Assim, os produtores tenderiam a reagir à expansão inicial da demanda agregada, aumentando a produção, os empregados trabalhando por mais horas e os desempregados aceitando trabalhos oferecidos a salários nominais menores. Todavia, apesar de admitir que a demanda agregada possa ter expansão no curto prazo, fazendo a taxa de desemprego diminuir abaixo da taxa natural, Friedman (1968) afirmou que os efeitos de longo prazo são outros.

Mas isto descreve apenas os efeitos iniciais. Como os preços de venda de produtos, tipicamente, reagem a uma elevação imprevista da demanda nominal, mais depressa do que os preços de fatores de produção, os salários reais recebidos baixaram, embora os salários reais esperados pelos empregados tenham subido, uma vez que os empregados avaliaram implicitamente os salários oferecidos de acordo com o nível de preços anterior. Na verdade, a simultânea queda ex post nos salários reais para os empregadores e elevação ex ante para empregados é o que possibilitou o aumento do emprego. Mas o declínio ex post dos salários reais logo passará a afetar as expectativas. Os empregados começarão a perceber os preços crescentes das coisas que eles compram e a exigir salários nominais mais altos para o futuro. O desemprego de mercado está abaixo do nível natural. Há um excesso de demanda por mão-de-obra, e assim os salários reais tenderão a subir em direção a seu nível inicial. (FRIEDMAN, 1968, p. 10).

A discussão apresentada anteriormente prossegue até os dias atuais em controvérsias que prevalecem com outras correntes de pensamento, tais como as denominadas escolas novo-clássica, novo-keynesiana e pós-keynesiana.

Os novos-clássicos desenvolveram uma hipótese de formação das expectativas (hipótese de expectativas racionais), na qual, além das ex- 
periências vivenciadas no passado, os agentes econômicos contemplariam ainda o conhecimento do modelo de funcionamento da economia e um conjunto de informações sobre as variáveis relevantes até o momento imediatamente anterior à tomada de decisões. Desta forma, o agente econômico teria uma chance muito reduzida de cometer erros sobre os acontecimentos futuros da economia, o que faria desaparecer a possibilidade de erros sistemáticos.

Com base nas expectativas racionais e na crença de perfeita flexibilidade de preços e salários, para os novos-clássicos, a política monetária teria poucas condições de ser utilizada para alterar o emprego e o produto. Qualquer anúncio sobre medida de política monetária faria com que os agentes antecipassem suas ações, tornando ineficazes as medidas anunciadas. Neste sentido, os novos-clássicos afirmavam que os agentes não possuíam ilusão monetária, contrariamente ao que afirmavam os monetaristas. Se o banco central divulga como proposta de política uma contração monetária, os agentes econômicos, conhecedores do modelo, verificariam que haverá uma elevação da taxa de juros, que deverá diminuir o nível de produção e o nível geral dos preços da economia. Sendo assim, os agentes antecipam a diminuição dos preços, fazendo com que não haja nenhuma interferência nas variáveis reais como a produção e o emprego.

Os novos-clássicos, ressalte-se, admitem que a política monetária afete as variáveis reais quando os agentes econômicos forem surpreendidos pelas medidas adotadas. No caso de uma contração monetária não esperada pelos agentes, haveria uma possibilidade de retração da atividade até que fosse atingido o nível de preços. O mesmo aconteceria durante períodos de expansão, mas com menor intensidade que nos períodos de retração. O horizonte temporal seria o de curto prazo, uma vez que os agentes teriam oportunidade de rever suas expectativas, fazendo com que houvesse retorno das variáveis reais ao nível anterior de equilíbrio.

Em síntese, todo o funcionamento da economia para os novosclássicos ocorre com a flexibilização plena de preços e salários. Devido a isso é que a política monetária anunciada anteriormente a sua implementação permitiria o ajuste dos agentes de acordo com a sua expectativa. Em contraposição, os novos-keynesianos buscaram enfatizar a participação de componentes microeconômicos na determinação da rigidez de preços e salários. O objetivo principal era o de dar maior sustentação às causas do desemprego involuntário, o que justificaria a impossibilidade de ajuste por parte dos agentes e, com isso, a influência da política monetária dentro da economia real, mesmo com os agentes tendo expectativas racionais.

Para tentar explicar a rigidez de preços e salários, os novos keynesianos desenvolveram duas teorias: Custos de Menu (Мепи Costs) e 
Salário Eficiência (TAYLOR, 1988). A primeira busca elucidar a rigidez dos preços por meio da restrição que os agentes econômicos teriam em modificar sua lista de preços, pois os custos em reproduzir e distribuir os catálogos com os novos preços seriam superiores aos eventuais ganhos em alterá-los. Por sua vez, a teoria do salário eficiência centra-se no incentivo de um salário real elevado para que o trabalhador tenha também produtividade elevada.

Partindo destas idéias básicas do pensamento novo-keynesiano, segundo Campbell e Mankiw (1989), é que a política monetária teria um importante papel em determinar as flutuações da demanda agregada e da produção. Isto porque a modificação da taxa de juros realizada pelo banco central teria a função de alterar o crédito, o que alteraria os gastos e, com isso, modificaria o produto dentro do horizonte de curto prazo, devido à rigidez dos preços e salários. A partir da persistência da nova situação e com a possibilidade dos custos de ajuste compensarem, é que os preços e salários seriam alterados, ficando no horizonte de longo prazo o retorno dos níveis de produção à situação inicial.

Outra corrente teórica de destaque nesse debate é a dos póskeynesianos. Estes mantiveram e reafirmaram alguns conceitos de Keynes que a síntese neoclássica deixou de lado. Segundo Davidson (1994), a leitura da Teoria Geral indica que a política monetária afeta o nível de emprego e, portanto, as variáveis reais da economia. A moeda não é neutra apenas no curto prazo, mas, dependendo das ações dos agentes econômicos, ela pode também ser não-neutra no longo prazo.

Para que a política monetária possa afetar o emprego, é necessário que a postura do banco central quanto à operacionalidade seja consistente com as demais políticas empreendidas pelo governo, havendo coordenação entre suas ações, conforme destaca Chick (1993). Dentro desta perspectiva, os pós-keynesianos não são favoráveis a um banco central independente, diferentemente dos novos-clássicos. Defendem, sim, uma coordenação das ações de política econômica de forma geral.

De acordo com Davidson (1994), o papel da política monetária para aumentar o produto seria transformar moeda-ativo em moeda meio de troca, ou seja, induzir a viagem de moeda da circulação financeira para a circulação industrial. Estimular-se-ia, assim, a composição de portfólios que contenham ativos comercializados na circulação industrial com baixa liquidez, mas capazes de render ex ante lucros compensadores em relação aos juros oferecidos pelos ativos líquidos da circulação financeira.

Portanto, a política monetária, segundo os pós-keynesianos, não afetaria diretamente o produto, mas induziria os indivíduos, bancos e firmas 
a terem um comportamento que, ao perceberem um aumento de moeda realizado pelo banco central, faria com que esta moeda seguisse para a aquisição de ativos pouco líquidos ou aquisição de ativos financeiros em mercados primários de firmas não financeiras, tendo assim efeito pleno sobre o produto e o emprego. ${ }^{9}$

Nas últimas duas décadas, esses vários posicionamentos teóricos foram alimentando as discussões sobre os canais de transmissão da política monetária. Todavia, dadas as necessidades imediatas dos gestores monetários (bancos centrais), tais discussões assumiram uma conotação mais pragmática, como mostrado na próxima seção.

\section{PRINCIPAIS CANAIS DE TRANSMISSÃO DA POLÍTICA MONETÁRIA: BREVE EXPOSIÇÃO TEÓRICA}

A discussão teórica recente acerca do tema mecanismos de transmissão monetária tem como marco o simpósio "The Monetary Transmission Mechanism", realizado em 1995, e os artigos publicados no Journal of Economic Perspectives do mesmo ano. Os textos apresentados neste Simpósio foram os de Bernanke e Gertler (1995), que realizaram uma crítica à visão tradicional da taxa de juros, evidenciando a existência de um canal do crédito; Meltzer (1995), realizando uma crítica monetarista ao modelo tradicional de transmissão via taxa de juros; Taylor (1995), que defendeu a utilização de trabalho econométrico para estudar e comprovar a preponderância do mecanismo de transmissão via taxa de juros; Obstfeld e Rogoff (1995), discutindo o regime de taxa de câmbio e as crises financeiras; e Mishkin (1995), com um breve resumo da discussão realizada no Simpósio.

Deste Simpósio até os dias atuais muito foi discutido, com avanços conceituais e explicitação de alguns pontos divergentes que serão tratados nesta seção. Assim, busca-se realizar uma apresentação dos principais canais de transmissão da política monetária, de acordo com algumas posições teóricas, procurando sempre situar as discussões entre os diferentes pontos de vista.

${ }^{9}$ Esta visão sintética da contribuição pós-keynesiana cumpre parte da necessidade deste trabalho, porém, para uma visão mais aprofundada da contribuição desta escola, consultar Costa (1994), Fiocca (2000) e também Rogers (1989). 


\section{Canal da taxa de juros}

Segundo Mishkin (1995, 1996 e 1998), o canal da taxa de juros é o mais tradicional canal de transmissão da política monetária. A presença desta posição tornou-se preponderante, principalmente após a sistematização de Hicks (1937) por meio do desenvolvimento do modelo IS-LM. Lembra-se que neste modelo: a) a curva IS demonstra os pontos de equilíbrio no mercado de bens e serviços, enquanto que a curva LM demonstra os pontos de equilíbrio no mercado monetário; b) a oferta de moeda é tomada como uma variável exógena, sendo determinada pelo Banco Central; c) a demanda por moeda relaciona-se diretamente com o nível da renda e inversamente com a taxa real de juros; d) no horizonte de curto prazo, os preços são considerados rígidos, implicando que qualquer alteração na quantidade nominal de moeda provoca modificações na quantidade real de moeda presente no mercado monetário e, desta forma, a oferta e a demanda estabelecem-se no ponto de equilíbrio num determinado nível de taxa de juros, sempre lembrando que as variáveis exógenas são mantidas no seu nível inicial.

De acordo com o modelo IS-LM, um aumento na oferta de moeda (mantida inalterada a função de demanda por moeda) faz com que diminua a taxa de juros real de equilíbrio no mercado monetário. A diminuição da taxa de juros afeta as decisões sobre o investimento das empresas, tornando viáveis alguns projetos que antes estavam "engavetados", provocando assim um aumento no dispêndio com investimento por parte das empresas. Como os gastos dos consumidores com bens duráveis e com moradia também podem ser considerados positivamente sensíveis à taxa de juros, de forma que quando essa cai, tais componentes da demanda agregada aumentam. Os aumentos do investimento das empresas e do dispêndio dos consumidores provocam um aumento sobre a renda que, por sua vez, aumenta o consumo e cria um efeito multiplicador na renda final, a qual se ajusta ao novo nível de taxa de juros real e incita o aumento da demanda agregada, da renda e, por conseqüência, do produto. Os elos da cadeia de transmissão são assim explicitados, como já apontava Keynes (1985). Uma defesa desta posição pode ser encontrada em Hicks (1992), quando esse apresenta a taxa de juros de curto prazo como responsável por modificar as transações comerciais, de acordo com as proposições de Hawtrey. ${ }^{10}$ Esta flutuação de curto prazo deve permitir o retorno a um nível esperado pelos agentes no

\footnotetext{
${ }^{10}$ Ver Hicks (1992, p 148).
} 
longo prazo, isto porque as taxas de juros de longo prazo é que deverão regular o investimento em capital fixo.

Com o objetivo de alcançar melhor entendimento dos mecanismos de transmissão com base no canal da taxa de juros, Taylor (1995) defende a utilização de trabalhos empíricos cada vez mais aprofundados. Ademais, percebe-se que a ênfase dada por Taylor (1995) é sobre os preços estabelecidos no mercado financeiro e não sobre as quantidades dos ativos presentes neste mercado (base monetária, crédito bancário, oferta de títulos do governo). Assim, as variáveis determinantes seriam: taxa de câmbio, taxa de juros de curto prazo e taxa de juros de longo prazo.

Ao apresentar um modelo com o objetivo de explicitar o funcionamento do canal de juros, Taylor (1995) parte do princípio de que uma política monetária restritiva aumenta a taxa de juros nominal no curto prazo. Isso, combinado à assunção de agentes econômicos com expectativas racionais e os preços e salários nominais rígidos no curto prazo, implica também alta da taxa de juros real de curto prazo, aumentando as expectativas quanto ao nível futuro da taxa de juros, devido à antecipação das ações realizadas pelos agentes. Este aumento na taxa de juros de longo prazo faz declinar o investimento das empresas, a construção de residências e o consumo de bens duráveis, ocasionando, assim, queda no produto.

Taylor (1995) tratou ainda dos efeitos circulares da política monetária, utilizando-se de modelos de equilíbrio de portfólio e da função de reação dos bancos centrais. Os bancos centrais agiriam sobre a taxa de juros de curto prazo, mas reagiriam a mudanças do panorama econômico por meio de certas regras como, por exemplo, o aperto monetário quando percebessem uma aceleração do nível de atividade que poderia causar pressões inflacionárias. Desta forma, a taxa de juros de longo prazo dependeria das expectativas dos agentes quanto à manutenção das regras de política monetária ao longo do tempo.

A posição de Taylor (1995) sobre o canal da taxa de juros cria novos fundamentos para a compreensão da transmissão da política monetária por este caminho, buscando, nas expectativas racionais e também no comportamento dos bancos centrais na gestão da política monetária, uma forma mais convincente de apresentar o efeito taxa de juros sobre o investimento, o consumo e o produto. Porém, o modelo recebeu críticas de Meltzer (1995) e Bernanke; Gertler (1995).

De acordo com Meltzer (1995), para um economista monetarista, a visão do processo de transmissão apresentada por Taylor (1995), e também a apresentada pelo modelo IS-LM, são consideradas restritivas e mecânicas. As modificações na quantidade nominal e real de moeda não alteram simples- 
mente a taxa de juros de curto prazo ou o custo dos empréstimos, mas também os preços relativos dos demais ativos reais e financeiros, denominados em moeda doméstica e estrangeira. Sua crítica ao modelo pode ser assim resumida:

The IS-LM model omits important features of the transmission process. First, the model neglects the adjustment of asset stocks as new investment in capital accumulates. Second, it leaves open whether the single rate of interest is a short-term rate, considered relevant for the demand for money, or a long-term rate relevant for investment and capital accumulation. Third, there is no role for financial intermediaries; money is either the monetary base or directly proportional to the monetary base. Forth, the model leaves open whether money substitutes for bonds only or for a full range of assets including both bonds and real capital. On the latter interpretation, bonds and real capital are perfect substitutes in portfolios (or only differ by a constant risk premium). Fifth, many of the changes in shortterm interest rate are transitory disturbances that not affect spending decisions. IS-LM does not distinguish these transitory movements from permanent or persistent changes in nominal and real returns. (MELTZER, 1995, p. 52).

A crítica realizada por Bernanke e Gertler (1995) tem um caráter diferente da de Meltzer, levantando alguns problemas que são omitidos na análise de Taylor (1995) e do modelo IS-LM, principalmente quanto à ligação entre a alteração na taxa de juros e o efeito nas variáveis reais. Os autores chamaram este intervalo de "caixa preta", pois não é tratado pelo modelo tradicional. Para eles, o canal do crédito levanta hipóteses que permitem explicitar os elos de interação entre as variáveis, passando por particularidades de atuação do mercado financeiro, pois a concessão e a tomada de crédito sofrem os efeitos de informação assimétrica (assimetric information) ${ }^{11}$, principalmente de seleção adversa (adverse selection) ${ }^{12}$ e de risco moral

11 Informação assimétrica é a desigualdade existente nos mercados financeiros, nos quais uma parte não sabe o suficiente sobre a outra parte para tomar decisões precisas.

${ }^{12}$ Seleção adversa é o problema criado pela informação assimétrica antes que a transação ocorra. No mercado financeiro ocorre quando os tomadores potenciais, que são os mais prováveis de produzir um resultado indesejável (adverso) - os maus riscos de crédito -, são aqueles que mais ativamente buscam um empréstimo e, portanto, são os mais prováveis de serem selecionados. Neste caso, os emprestadores decidem por não conceder o crédito, mesmo que os tomadores estejam dispostos a pagar pelo risco. 
(moral hazard $)^{13}$. A exposição do canal do crédito é realizada no último item desta seção, com maiores detalhes.

\section{Canal da taxa de câmbio}

O canal da taxa de câmbio depende da alteração na taxa de câmbio provocada por mudança na política monetária. De acordo com Mishkin (1996), quando a taxa de juros doméstica diminui, por conta de um aumento na quantidade ofertada de moeda, as aplicações realizadas em ativos denominados em moeda doméstica tornam-se menos atrativas que as aplicações realizadas em ativos denominados em moeda estrangeira. A busca por aplicações em moeda estrangeira provoca uma depreciação (no caso de regime de taxa de câmbio flutuante) na taxa de câmbio. Esta depreciação impulsiona as exportações e restringe as importações, aumentando o saldo em conta corrente e o dispêndio com bens domésticos, o que cria um efeito multiplicador da renda, aumentando assim o produto. Esta posição também é compartilhada por Hicks (1992).

\section{Outros Canais de Preços de Ativos (Other Asset Prices Channels)}

Este canal concerne aos impactos da política monetária sobre os preços de imóveis, ações, títulos e outros. Mishkin (1996) enfatiza que o canal de outros preços de ativos pode ser analisado por meio dos preços das ações das empresas, visto sob dois aspectos: um pelo q de Tobin, que afeta o investimento; e outro, pelo efeito riqueza sobre o consumo.

\section{Análise via q de Tobin}

O q de Tobin é uma razão entre o preço de mercado do capital das firmas (que reflete o valor presente dos lucros esperados dessas firmas), no numerador, e o custo de reposição deste capital, no denominador. Se o q for maior do que 1 (um), espelha um preço de mercado das firmas superior ao custo de reposição do respectivo capital dessas firmas, tornando-se portan-

${ }^{13}$ Risco moral é o problema criado pela informação assimétrica depois que ocorre a transação. O risco moral nos mercados financeiros é o risco de que o tomador se comprometa com atividades que sejam indesejáveis (imorais) do ponto de vista do emprestador, porque elas diminuem a probabilidade de que o empréstimo seja pago. Sendo assim, os emprestadores podem decidir que o melhor é não conceder o empréstimo. 
to, incentivo ao aumento do investimento. Por outro lado, caso o q seja menor do que 1 (um), o preço de mercado do capital da firma é menor do que o custo de reposição. Nesse caso, a preferência é, então, deixar o capital se depreciar, não ocorrendo investimento. Assim, existiria uma relação entre o q de Tobin e o investimento. A política monetária afetaria o preço das ações da seguinte forma: o aumento da oferta de moeda provocaria alta na demanda, agregada e, tudo mais constante, nas expectativas de lucros das firmas. Por conseguinte, com a maior demanda haveria uma ascendência da demanda por ações e, conseqüentemente, nos seus preços. A subida nos preços das ações elevaria o q de Tobin, aumentando o investimento e, com isso, o produto. Há outra forma de verificar esta transmissão: um aumento da oferta de moeda reduziria a taxa de juros sobre os títulos da dívida, de forma que haveria uma queda dos rendimentos sobre as alternativas às ações. Isso faria com que as ações se tornassem mais atraentes em relação aos títulos, de maneira que sua demanda aumentasse, seu preço subisse e, portanto, seu rendimento diminuísse, elevando o q de Tobin, o investimento e o produto.

\section{Análise via efeito riqueza}

Outra forma de tratamento deste canal é constatar que os consumidores possuem balanços patrimoniais capazes de afetar suas decisões de gastos. Como mostra Modigliani (1971), o consumo é considerado como o gasto em bens não-duráveis e serviços, desconsiderando, assim, os bens duráveis de consumo. A composição patrimonial do consumidor será formada pela riqueza herdada e pela acumulação de excedente ao longo da vida produtiva. Parte significativa deste patrimônio fica na forma de riqueza financeira, sendo composta, em grande parte, por ações. A hipótese do ciclo da vida condiciona a determinação do consumo, não pela renda corrente, mas pela riqueza, que - por sua vez - determina o nível de consumo, durante a vida do indivíduo. Portanto, mudanças na riqueza podem ser a principal causa para provocar alteração no consumo.

Cumprindo a mesma trajetória do q de Tobin, uma política monetária expansionista elevaria o preço das ações e, daí, a riqueza financeira dos agentes. Esta elevação provocaria um efeito expansivo sobre o consumo; por conseguinte, um aumento multiplicado na renda e, conseqüentemente, no produto. 


\section{Canal do crédito}

Em Mishkin (1996), o canal do crédito representa uma interpretação alternativa sobre como a taxa de juros afetaria a economia. A análise deste mecanismo enfatiza a presença de informação assimétrica no mercado financeiro. Em oposição ao canal da taxa de juros, o canal do crédito estabelece que os mercados financeiros não trabalham de forma perfeita, havendo imperfeições significativas para a transmissão da política monetária.

Segundo Bernanke e Gertler (1995), a taxa de juros assume um papel preponderante - mas não determinante - na transmissão das modificações da política monetária. O canal do crédito é um mecanismo de transmissão que põe em evidência os problemas existentes no mercado financeiro, desde a existência de informação assimétrica e risco moral até a composição, organização e atuação do setor financeiro e do setor produtivo. Consideram os autores que o mercado financeiro não trabalha apenas com títulos e moeda, mas com a carteira de ativos dos agentes sendo muito mais diversificada do que assume, por exemplo, o modelo IS-LM.

De fato, existiriam dois mecanismos de transmissão monetária derivados dos problemas de informação assimétrica nos mercados de crédito: o mecanismo de empréstimos bancários (banking lending channel) e o mecanismo que funcionaria por meio dos efeitos sobre os balanços patrimoniais das firmas e dos indivíduos (balance sheet channel).

Segundo Mishkin (1995, 1996 e 1998) e Bernanke e Gertler (1995), o canal de empréstimos bancários surge do reconhecimento da função especial que os bancos desempenham no sistema financeiro, o que os torna especialmente bem supridos de informação para avaliar a concessão de crédito. A maioria dos tomadores de crédito necessitaria dos bancos porque não conseguiria chegar até o mercado de capitais e tomar recursos diretamente dos investidores. Isto significaria que existiriam tomadores que conseguiriam crédito apenas quando os bancos o colocasse a sua disposição. Os bancos, para poderem oferecer crédito, teriam que captar recursos no mercado por meio da captação de fundos. Esta captação dependeria diretamente do volume de moeda em circulação: quanto maior o volume de moeda, maior seria a captação e, por conseguinte, a disponibilidade de empréstimos bancários aos agentes. Desde que não houvesse uma perfeita substituição de depósitos bancários do varejo com outros fundos, o canal de transmissão monetária funcionaria da seguinte forma: um aumento da oferta de moeda aumenta as reservas e os depósitos bancários, elevando a quantidade de empréstimos nos bancos. Estes empréstimos são direcionados para certos 
tomadores que irão realizar investimento ou consumo, aumentando, com isso, o produto.

Este canal é determinante para a expansão das pequenas empresas; afinal grande parte dessas são altamente dependentes de empréstimos bancários. Portanto, para a expansão de seus negócios, há necessidade de terem acesso ao mercado de crédito dos bancos, diferentemente das grandes empresas, capazes de captar recursos no mercado bancário internacional e nos mercados de capitais.

Ainda sobre o canal de empréstimos bancários, é interessante destacar que o impacto da política monetária sobre o volume de empréstimos depende também do porte dos bancos. Os pequenos e médios bancos não possuem facilidade de acesso aos mercados financeiros internacionais e ficam em dificuldade diante de uma contração da moeda, diminuindo mais que proporcionalmente o volume de empréstimos aos tomadores. Por outro lado, os grandes bancos, por terem maior acesso aos mercados, conseguiriam manter os empréstimos em níveis mais elevados que os pequenos e médios diante de uma política monetária contracionista.

O canal do balanço (balance-sheet channel) também se deriva da presença de problemas de informação assimétrica. A política monetária pode afetar as empresas da seguinte forma: uma diminuição da oferta monetária provoca um aumento na taxa de juros, o que pode imprimir uma tendência de queda no preço das ações e esta queda no preço diminuir o valor patrimonial das firmas. A diminuição do valor das firmas aumenta a possibilidade de seleção adversa e do risco moral, criando dificuldade para as firmas conseguirem tomar recursos para continuar o processo produtivo e também levarem adiante suas decisões de investimentos. O resultado pode ser uma queda no produto e no emprego.

Outra forma de análise é feita por meio do fluxo de caixa das empresas. Por exemplo, um aumento da oferta de moeda diminui a taxa de juros nominal, causando uma melhoria na composição patrimonial das empresas. Esta melhoria pode ser causada pela queda no custo de capital de giro da empresa, pelo menor valor de juros pagos sobre as obrigações e sobre um menor custo de oportunidade da manutenção de recursos em estoque e outras formas fixas. Estas possíveis ocorrências provocam um aumento no fluxo de caixa, o que melhora a posição financeira da empresa, reduzindo, então, os problemas de seleção adversa e de risco moral, aumentando a possibilidade de tomada de novos empréstimos que aumentariam o investimento e criando efeito multiplicador de aumento no produto e no emprego.

Uma terceira forma de avaliar este canal é por meio de variação não-antecipada no nível geral de preços. Uma expansão monetária pode 
provocar um aumento não-antecipado no nível geral de preços. Com o aumento de preços, há a possibilidade de diminuição do valor do passivo das empresas, devido à queda na taxa de juros real, melhorando o equilíbrio entre os haveres e as obrigações, caindo a possibilidade de seleção adversa e do risco moral. Os empréstimos podem sofrer um aumento, o que criaria um clima favorável a novos investimentos e, por conseqüência, um aumento do produto.

A partir da posição apresentada por Bernanke e Gertler (1995), fica mais consistente o entendimento sobre a transmissão de modificações da política monetária para o restante da economia. Torna-se evidente que os impactos causados por mudanças na taxa de juros devem atingir de forma diferenciada as empresas, os bancos e, principalmente, as diferentes regiões, de acordo com a sua estrutura produtiva e bancária, e não de maneira uniforme, como assume Taylor (1995).

\section{CONCLUSÃo}

Este trabalho buscou apresentar uma visão geral sobre os mecanismos de transmissão da política monetária. Porém, o início da discussão obrigatoriamente passou pela controvérsia dentro da teoria monetária sobre o papel da moeda na economia e sua capacidade em afetar as variáveis reais.

A primeira seção tratou de sintetizar o debate ocorrido entre as correntes da economia monetária no período pós-guerra, principalmente durante as décadas de 1940-1960. Os keynesianos da síntese neoclássica defendiam as intervenções na economia por meio de política fiscal, por entenderem que a política monetária afetaria muito pouco o produto e o emprego, dada a baixa sensibilidade do investimento à taxa de juros. Os monetaristas apresentaram argumentação de que a moeda tem sim efeito sobre a economia, mas afetaria o produto apenas no curto prazo, antes que os agentes pudessem modificar suas posições. No longo prazo, levaria apenas a alterações nos preços.

O debate entre estas duas correntes provocou uma evolução no tratamento da política monetária e, principalmente, na sua utilização pelas autoridades econômicas a partir da década de 1970. A evolução das idéias fez surgir outras correntes de pensamento, como os novos-clássicos, os novos-keynesianos e os pós-keynesianos, mas o ponto de destaque é que Keynes, na Teoria Geral, já havia realizado um tratamento dos mecanismos de transmissão de forma mais clara que muitos de seus seguidores e adversários.

Respeitando esta controvérsia, a segunda seção apresentou os mecanismos de transmissão da política monetária, baseado nas discussões 
realizadas durante a década de 1990. Alguns canais de transmissão foram destacados, de acordo com as diferentes posições teóricas. O canal da taxa de juros, defendido principalmente por Taylor (1995), apresentou a visão da teoria keynesiana, sintetizada no modelo IS-LM, mas com algumas contribuições da corrente dos novos-clássicos, como o conceito de expectativas racionais. O canal de taxa de câmbio foi apresentado como a seqüência do canal de taxa de juros para uma economia aberta, com as implicações da taxa de juros sobre a taxa de câmbio e desta sobre as variáveis reais da economia e os fluxos de capitais. O canal do crédito apresentou a existência de particularidades nos mercados financeiros, que acabam por interferir na propagação de mudanças na taxa de juros para as variáveis reais da economia, principalmente quanto à presença de informação assimétrica entre tomadores e cedentes de crédito. Finalizando a discussão, apresentou-se a perspectiva monetarista da importância de outros canais de preços de ativos que interferem na transmissão da política monetária.

Os mecanismos de transmissão discutidos permitem que os pesquisadores possam buscar a verificação dos impactos que as mudanças na política monetária podem provocar na economia. Dentro do objetivo deste trabalho, discutir tanto o conhecimento dos pressupostos teóricos quanto os resultados empíricos obtidos pelas diferentes correntes de pensamento são de fundamental importância para a discussão vigente em Economia Monetária.

\section{RESUMO}

Este trabalho busca apresentar uma visão geral sobre os mecanismos de transmissão da política monetária. O início da discussão obrigatoriamente passa pela controvérsia dentro da teoria monetária sobre o papel da moeda na economia e sua capacidade em afetar as variáveis reais. Sintetiza-se o debate ocorrido entre as correntes da economia monetária no período pós-guerra, entre os keynesianos da síntese neoclássica e os monetaristas. A evolução das idéias fez surgir outras correntes de pensamento, como os novos-clássicos, os novoskeynesianos e os pós-keynesianos, mas o ponto de destaque é que Keynes, na Teoria Geral, já havia realizado um tratamento dos mecanismos de transmissão de forma mais clara que muitos de seus seguidores e adversários. Respeitando esta controvérsia, o trabalho apresenta os mecanismos de transmissão da política monetária, baseado nas discussões realizadas durante a década de 1990. 
Palavras-chave: política monetária, mecanismos de transmissão, Keynes.

\begin{abstract}
This work search to present a general view on the transmission mechanisms of the monetary policy. The beginning of the discussion obligatorily raisin for the controversy inside of the monetary theory on the paper of the coin in the economy and its capacity in affecting the real variables. The debate is synthesized happened among the currents of the monetary economy in the postwar period, between the keynesians of the neoclassical synthesis and the monetarists. The evolution of the ideas made to appear other thought currents, as the new-classic ones, the new-keynesians and the post-keynesians, but the prominence point is that Keynes, in the General Theory, had already accomplished a treatment of the transmission mechanisms in a clearer way than many of his followers and opponents. Respecting this controversy, the work presents the transmission mechanisms of the monetary policy, based on the discussions accomplished during the decade of 1990 .

Key-words: monetary policy, transmission mechanisms, Keynes.
\end{abstract}

\title{
REFERÊNCIAS
}

BANK OF ENGLAND. The Transmission Mechanism of Monetary Policy. The Monetary Policy Committee, 1999. (mimeo).

BERNANKE, B. S.; GERTLER, M. Inside the Black Box: the Credit Channel of Monetary Policy Transmission. The Journal of Economic Perspectives, v. 9, n. 4, 1995.

BIS (BANK FOR INTERNATIONAL SETTLEMENTS). The Transmission Of Monetary Policy in Emerging Market Economies. Policy Papers, n. 3. Basle: jan. 1998.

Implementing Monetary Policy in Emerging Market Economies. Policy Papers, n. 6. Basle, 1999.

BLINDER, A S. Bancos centrais: teoria e prática. São Paulo: Ed. 34, 1999.

BORIO, C.E.V. Monetary Policy Operating Procedures in Industrial Countries. BIS Working Papers, n. 40, Basle: mar. 1997.

CAMPBELL. J. Y; MANKIW, N. G. International Evidence on the Persistence of Economic Flutuations. NBER Working Paper, n. 2498, 1989.

CHICK, V. Macroeconomia após Keynes: um reexame da teoria geral. São Paulo: Forense Universitária, 1993. 
FONSECA, M. W. DA; VASCONCELOS, M. R. Efeitos reais da política monetária...

COSTA. F. N. Por uma teoria alternativa da moeda. Campinas, 1994. Tese ( Livre Docência) - Unicamp.

Mecanismos de transmissão monetária: interação e iteração. Economia $e$ Sociedade, Campinas, Unicamp, n. 5, p. 159-179, dez. 1995.

Economia monetária e financeira: uma abordagem pluralista. São Paulo: Makron Books, 1999.

DAVIDSON, P. Post Keynesian Macroeconomic Theory. London: Edward Elgar Publishing, 1994.

FIOCCA, D. A oferta de moeda na macroeconomia Keynesiana. São Paulo: Paz e Terra, 2000.

FISCHER, I. The Purchasing Power of Money. New York: Kelley, 1963 (ed. original, 1911).

FRIEDMAN, M. Quantity Theory of Money. In: EATWELL, J.; MILGATE, M.; NEWMAN, P. (Eds.). The New Palgrave: Money. London: The MacMillan Press, 1990. The Role of Monetary Policy. American Economic Review, n. 58, mar. 1968.

GREENWALD, Bruce; STIGLITZ, Joseph E. Towards a New Paradigm for Monetary Economics. 2002. (mimeo).

HICKS, J. Mr. Keynes and the Classics: A Suggested Interpretation. Econometrica, 1937. p. 147-159.

. Uma teoria monetária do mercado. Lisboa: Dom Quixote, 1992.

KEYNES, J.M. A teoria geral do emprego, do juro e da moeda. São Paulo: Nova Cultural, 1985. (Os Economistas).

LAWSON, T. Economics and Reality. London: Routledge, 1997.

MANKIW, N.G. Macroeconomia. 3. ed. Rio de Janeiro: LTC, 1998.

MELTZER, A. H. Monetary, Credit (and Other) Transmission Processes: A Monetarist Perspective. The Journal of Economic Perspectives, v. 9, n. 4, 1995.

MISHKIN, F. S. The Economics of Money, Banking and Financial Markets. Addisson Wesley Pub, 1998.

. The Channels of Monetary Transmission: Lessons For Monetary Policy. NBER Working Paper 5464, 1996.

Symposium on the Monetary Transmission Mechanism. The Journal of Economic Perspectives, v. 9, n. 4, 1995.

MODIGLIANI, F. Monetary policy and consumption. In: FEDERAL RESERVE BANK. Consumer spending and money policy: the linkages. Boston: Federal Reserve Bank, 1971. p. 9-84.

OBSTFELD, M.; ROGOFF, K. The Mirage of Fixed Exchange Rates. The Journal of Economic Perspectives, v. 9, n. 4, 1995.

ROGERS, C. Money, Interest and Capital: A Study in the Foundations of Monetary Theory. Cambridge: Cambridge University Press, 1989.

SCHUMPETER, Joseph A. History of Economic Analysis. New York: Oxford University Press, 1954. 
SILVA, L. A. S. A teoria quantitativa da moeda e a política monetária. Campinas, 1989. Tese ( Doutorado) - Unicamp.

TORRES, M. J. R. Operacionalidade da politica monetária no Brasil. Campinas, mar. 1999. Tese (Doutorado) - Unicamp.

TAYLOR, J. B. Improvements in Macroeconomic Stability: The Role of Wages and Prices. NBER Working Paper n. 1491, 1988.

The Monetary Transmission Mecanism: An Empirical Framework. The Journal of Economic Perspectives, v. 9, n. 4, 1995.

VAN'T DACK, J. Implementing Monetary Policy in Emerging Market Economies: An Overview of Issues. Policy Papers, Basle, n. 6, 1999. 